\title{
Wigmore's Chart Method
}

\section{JEAN GoodwIN Northwestern University}

\begin{abstract}
A generation before Beardsley, legal scholar John Henry Wigmore invented a scheme for representing arguments in a tree diagram, aimed to help advocates analyze the proof of facts at trial. In this essay, I describe Wigmore's "Chart Method" and trace its origin and influence. Wigmore, I argue, contributes to contemporary theory in two ways. His rhetorical approach to diagramming provides a novel perspective on problems about the theory of reasoning, premise adequacy, and dialectical obligations. Further, he advances a novel solution to the problem of assessing argument quality by representing the strength of argument in meeting objections.
\end{abstract}

Résumé: Une génération avant Beardsley, John Henry Wigmore, un expert of droit, a inventé une façon de représenter des arguments en diagrammes ayant la forme d'un arbre pour aider des avocats à analyser des preuves dans un procès. Je décris sa méthode et trace son origine et son influence. Je soutiens que Wigmore a contribué à la théorie d'argumentation de deux façons. Premièrement, son approche rhétorique aux diagrammes apporte une nouvelle perspective aux problèmes concernant la théorie du raisonnement, la suffisance des prémisses, et les obligations dialectiques. Par ailleurs, il avance une solution originale au problème de l'évaluation d'un argument en représentant la force d'un argument par sa capacité à répondre à des objections.

Keywords: J.H. Wigmore, A. Sidgwick, tree diagram, rhetoric, inference, argument, proof, premise adequacy, dialectical obligations, argument assessment.

The tree diagram-at present a widely-used tool for making apparent the structure of argument-is commonly said to have been invented by Monroe Beardsley in his 1950 Practical Logic (e.g., Copi, 1984, p. 85; Freeman, 1991, p. 1; Johnson, 2000, p. 129; Thomas, 1977, p. xvi). But 37 years before Beardsley, Professor John Henry Wigmore of the Northwestern University Law School had already proposed a "Chart Method" for capturing the structure of the proof of facts at trial. In this article, I aim to bring Wigmore's Chart Method to the attention of the argumentation community. I will begin with some background on Wigmore, his Charts, and their provenance, proceed by considering the perspective Wigmore's Method might contribute to some current debates within argumentation theory, 
and close by briefly remarking the influence the Chart Method has had and should have. In particular, I will develop throughout this essay the view that Wigmore's Charts deserve our regard because they adopt a distinctly rhetorical perspective on argument diagramming, and because they contribute a novel way to assess the argument quality by representing the strength of argument in meeting objections.

\section{The Man and his Charts}

Wigmore (1863-1943) was an early product of the modern, disciplinary American law school, a model he successfully imported to Northwestern University during his lengthy career as professor and dean of the law faculty. He is best known for his long-definitive Treatise on the Anglo-American System of Evidence in Trials at Common Law, including the Statutes and Judicial Decisions of All Jurisdictions in the United States, a massive and careful systematization of the case law in this complex subject, first published in 1904-5, and eventually reaching ten volumes in his final edition (Tillers \& Schum, 1988, pp. 914-5; Twining, 1985, p. 111). It appears that after launching this work, Wigmore became convinced that something was missing. The jurisprudence of evidence was and is dominated by the study of what cannot be evidence-that is, it concerns the so-called "exclusionary rules." The subject as traditionally defined includes little discussion of what advocates or judges of the facts are supposed to do with evidence, once it is admitted. Wigmore therefore seems to have set out to develop a method, as systematic as his Treatise, for analyzing what evidence does. A teaser, "The Problem of Proof," published in the Illinois Law Review in 1913, was quickly followed up by a thick textbook, The Principles of Judicial Proof, or, The Process of Proof, as given by Logic, Psychology and General Experience and Illustrated in Judicial Trials.' The Principles contained the miscellany of material typical of a legal casebook-discussions of particular problems of proof, records of sample trials for analysis, synopses of the earliest work on witness psychology. But the backbone of Wigmore's proposal, and the core of what he taught the students in his "Evidence I" class, was a Chart Method for diagramming what he called "judicial proof": the justification of conclusions of fact made by the decider(s) of fact (jury or judge) at a trial.

\section{Wigmore's Chart Method}

The Chart Method is a representational scheme with the following conventions (§\$29-32, pp. 52-6).

Lines. Lines represent what Wigmore sees as the probative processes available within the context of judicial proof.

1. The basic process of reasoning from premise to conclusion is represented by a upward arrow pointing from premise to conclusion. 
2. The process of refuting a conclusion by offering another premise is represented by a vertical arrow marked by a circle, pointing from that premise to the conclusion it refutes.

3. The process of raising an objection to a conclusion which "explain[s] away its effect" or "lessens [its] force" $(\S \S 29,30$, pp. 53$)$ is represented by a horizontal arrow extending to the right from the conclusion objected to. Wigmore calls this process "Explanation," and for the purposes of this paper, I will join him.

4. The process of refuting the Explanation and thus corroborating the original conclusion is represented by a line extending horizontally to the right from that. conclusion, marked by a cross.

Each of these processes may involve multiple premises; in that case, Wigmore allows lines from these premises to "connect" into a "composite" ( $\$ 33$, p. 57). To put this in contemporary terms, Wigmore represents all multiple-premise arguments as having linked structure.

The preliminary strength of an line, assessed while the Chart is being developed, is indicated by further inflecting the arrowhead or cross: doubling it to indicate special strength, putting a "?" by it for special weakness. After the entire Chart is finished and reviewed, the constructor's final strength assessment is indicated, with a small perpendicular line indicating weakness, and a cross indicating strength.

Shapes. Lines connect shapes which represent what Wigmore calls "facts," by which he must mean claimed facts, or facts offered for belief. Each shape is numbered, with the number referring to a statement collected in a "key list."

5. The fact of testimonial assertion (i.e., the fact that someone said something under oath) is represented by a square.

6. Explanations and refutations of Explanations are represented by triangles "pointing" horizontally.

7. All other facts are represented by circles.

Each shape can be further marked to reflect its source (" " = immediately present to the jury; "q" = judicially noticed); if unmarked, it is put forward as the conclusion of some reasoning.

If the fact tends to undermine the ultimate conclusion of the Chart, the base side of its shape is left off; if the fact is introduced at trial by the party opposed to the one preparing the chart, the top side of the shape is doubled.

Finally, the strength of the Charter's ultimate belief can be recorded within the shape as doubt ("?"), belief ("*" or more strongly "..") or disbelief ("0" or "00").

\section{An example}

Consider the example in Figure 1, a major branch of one of Wigmore's sample Charts ( $\$ 38$, pp. 62-66). The case concerns the alleged murder of Jedrusik by Umilian. 
Figure 1: Part of Wigmore's Chart of Commonwealth v. Umilian.

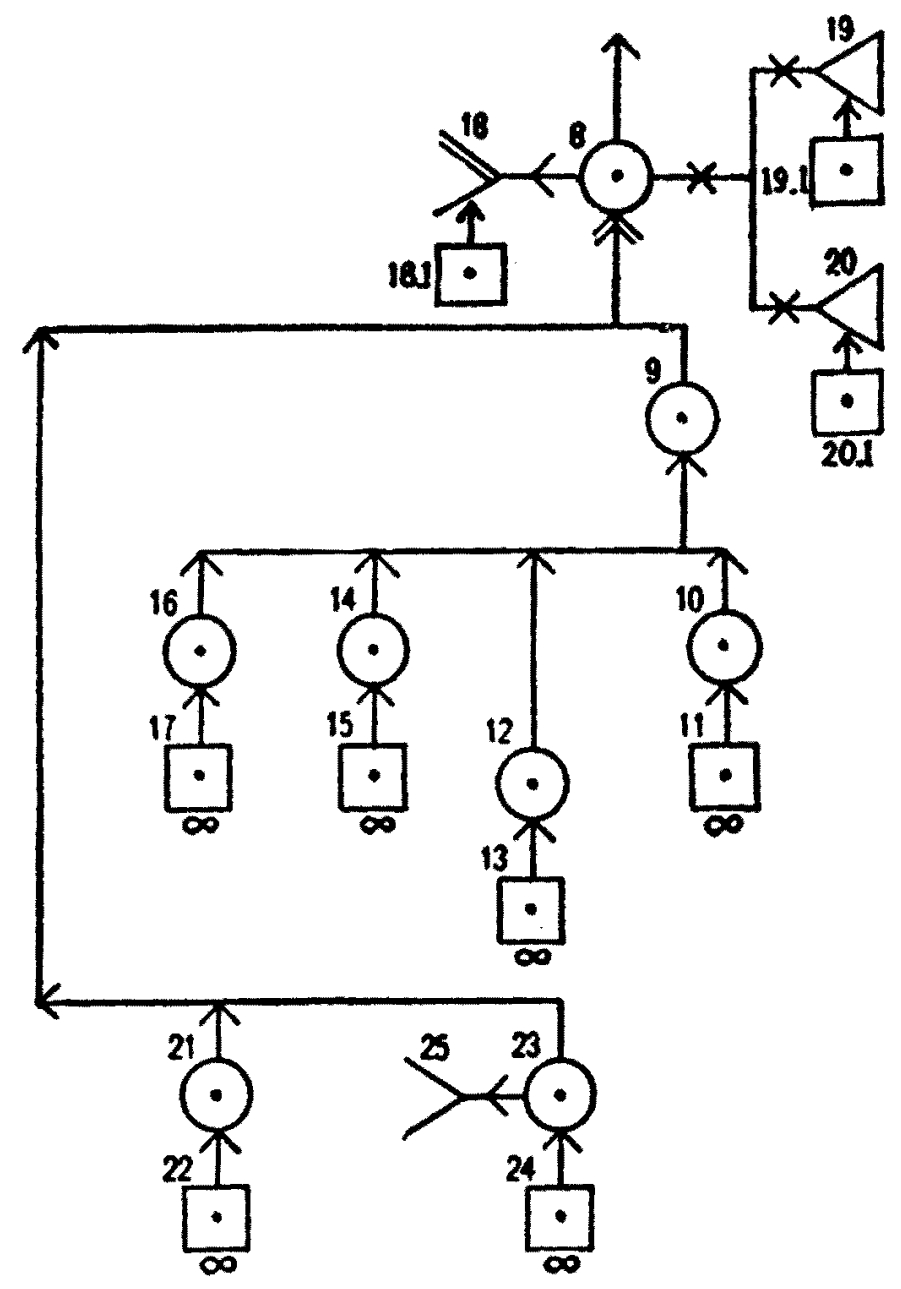

Key List for Commonwealth v. Umilian (1901)

8 [Umilian felt] Revengeful murderous emotion towards J[edrusik].

9 J. had falsely charged him [Umilian] with intended bigamy Nov. 18, and had tried thereby to prevent his marriage; thus tending to stir up such an emotion.

10 Letter received by priest, stating that $U$. already had family in old country.

11 Anon. witnesses to this.

$12 \mathrm{~J}$. was author of letter, though it was in fictitious name.

13 Anon. witnesses to this.

14 Letter communicated by priest to U., with refusal to perform marriage; refusal later withdrawn. 
15 Anon. witnesses to this.

16 Letter's statements were untrue.

17 Anon. witnesses to this.

18 U.'s marriage being finally performed, U. would not have had a strong feeling of revenge.

18.1 [Anon. witnesses to this.]

$19 \mathrm{~J}$. remaining in daily contact, wound must have rankled.

19.1 Witness to daily contact.

20 Wife remaining there, jealousy between $\mathrm{U}$. and J. probably continued.

20.1 Witness to wife remaining.

21 U. uttered threats and other hostile expressions between Nov. 18 and Dec. 31 .

22 Anon. witness to this.

23 U., on Dec. 31, charged J. to K[eith, their employer] with stealing K.'s goods.

24 Anon. witnesses to this.

25 Does not appear that these charges were false, hence not malicious.

The overall thrust of the argument is to establish statement 8 , which in turn establishes that Umilian had a motive for the crime. The first move is to justify (line from below) a passionate mental state by establishing an injury the murdered man did the accused; next to try to explain away (line to the left) that injury's impact due to the passage of time; and finally to reconfirm the emotion (line to the right) by giving reasons for its continued existence. Each assertion in the Chart is based (square below) on the testimony of witnesses, but since Wigmore is drawing the case from a sketchy appellate report as opposed to a complete trial transcript, he is not able to do anything more than indicate that there were such witnesses.

\section{Quellenforschung}

Whence did Wigmore draw this Chart Method? In the Principles, Wigmore cites only two logic books: W. Stanley Jevons' The Principles of Science and Alfred Sidgwick's Fallacies: A View of Logic from the Practical Side (1884). The former discusses the syllogism and scientific method; nothing which could be an ancestor of the Chart Method. From the latter, the work of an obscure cousin of the Ethics' famous author (see generally Nielsen, 1997), Wigmore does seem to have drawn the kernel of an idea. Sidgwick uses an arrow to express relations between terms (pp. 60, 68; for example, "Intolerance $\longrightarrow$ active hostility," pp. 63-4)one of many contemporary attempts to capture the syllogism in symbolic form (usefully reviewed by Venn, 1894, Chap. 20). But Sidgwick also allows these arrows to represent other relations, in particular relations between propositions, so that any argument may be expressed as " $\mathrm{R} \longrightarrow \mathrm{T}$," that is, "the truth of $\mathrm{R}$ [eason] indicates the truth of T[hesis]," or "Grant R, and T follows"" (pp. 100-1). And he further notes that in everyday argument, several propositions will commonly be "chained" together by such arrows (p. 210), although he does not provide any full diagram of such a chain. 
Wigmore's Chart Method seems to be built on two advances over Sidgwick's initial idea: first, a determination to stick to representing propositions and their relations, and second, a determination to represent all the propositions and relations necessary to reach a conclusion of fact at a trial. These two innovations seem to have been Wigmore's own, and it's clear that the second at least got him into trouble. Where the contemporary tree diagram needs only numbered circles and arrows to represent inferential steps, Wigmore has gone on to add two other shapes and three other kinds of lines, not to mention a host of assessment markers he himself doesn't use. Still, some of the Chart's excesses actually seem to be useful, or at least provocative, and that suggests we should ask why. To that question I now turn.

\section{Wigmore's Charts and Contemporary Argumentation Theory}

Any diagramming scheme is based more or less consciously on notions of what arguments are and how they work. At some points, Wigmore explicitly defends his Method; at others, his ideas have to be reconstructed from the choices he makes when designing his Charts. In the following, I survey several topics on which Wigmore's approach appears to contrast with contemporary views, or to cast a different light on contemporary problems. I develop in particular two main lines of attack. First, I sketch how Wigmore's Method reflects the interests of a specifically rhetorical orientation to argument diagramming, in contrast to the orientation generally adopted within informal logic. Last, I suggest that Wigmore's Method may contribute a new solution to the problem of representing the external strength of arguments, that is, the extent to which an argument can resist refutation.

\section{A rhetorical turn on argument diagramming}

The old conversation between logic and rhetoric has recently been renewed, with logic represented primarily by those enlisting under the banner of informal logic, and rhetoric by American scholars in Communications and English departments. ${ }^{2}$ Both parties to the conversation share an interest in a common material: argumentative practice. But each brings with it a tradition establishing rather different perspectives on the common subject. Wigmore's Chart Method provides an intriguing illustration of how a shift in perspective from informal logic to rhetoric can alter the problems that become visible. The Method is a diagramming scheme, one of the instruments traditional to the inform logical approach. Still, though he seems to have had no more contact with the rhetorical tradition than with the logical, Wigmore gives his Charts a rhetorical turn-a turn which accounts for some of their peculiarities, and also for some of their strengths. In the following subsections, I consider why Wigmore's apparently rhetorical perspective allows him to identify argument, inference and proof, to elide the difference between premise acceptability 
and premise truth, and to encounter a new problem establishing the limits of an arguer's obligation to develop her argument.

\section{What is being Charted?}

Within informal logic there have emerged increasingly precise distinctions among the logical relationship by which conclusions are entailed by premises, the mental process by which conclusions are inferred from premises, and the interpersonal or social activity by which conclusions are justified through premises (e.g., Johnson, 2000; Pinto, 1995). Wigmore recognizes something like these distinctions, but nevertheless holds that his Chart charts all three. Is this just sloppiness?

It's clear that Wigmore takes his Chart primarily to represent the thought processes of someone trying to make a decision-the "natural processes of the mind in dealing with the evidential facts" $(\S 1$, p. 5$)$. The Chart Method's elaborate set of symbols for making express the strength of interim and final beliefs is just one example of this attempt to represent all the motions of the mind.

Wigmore goes on to claim, however, that his Charts represent not just the "psychological" process of coming to belief, but also the correct process for deciding-a "logical" process ( $\$ 26$, p. 48$)$. In making this leap from the "is" to the "ought" of thought, it appears that Wigmore is making the optimistic working assumption that the decider's mental process is substantially sound. Now, however realistic this assumption might be in general, it does seem that Wigmore has good reason to make it in the context of judicial proof. At trial the decider is responsible for coming to a correct decision on an important matter. As Wigmore says, it is "our moral duty (in court) . . . to reach a belief corresponding to the actual facts; hence it is repugnant to us to contemplate that our belief is not as trustworthy as it could be" $(\$ 26, \mathrm{p} .47)$. To fulfill this obligation and avoid criticism, the decider must come to a decision that is defensible or justifiable, that is, the same decision that would be made by the correct method of reasoning. This provides the decider with strong encouragement to think through the case not just in any way, but in the best way. Under these conditions, inferring is indeed isomorphic with proving, and the Chart can simultaneously represent both.

This does not mean that Wigmore thinks there is some well-established method for deciding judicial cases. Quite the contrary; as Wigmore explains, the Chart "need not show us what our belief ought to be," for "no system of logic has yet discovered and established.

[the] laws" of correct reasoning on these questions $(\$ 28$, p. 50). And Wigmore is pessimistic that logic ever will: since the questions of past fact at the center of trials are not amenable to scientific verification; since a strictly logical method of deciding cases would take too long for the judicial setting; and since logic has as yet "done nothing practical" towards showing how a mixed mass of evidence can support a conclusion. "All that the scheme [of representation] can do for us is to make plain the entirety and details of our actual 
mental process," Wigmore concludes $(\$ 23$, p. 50$)$. But such metacognition is indeed an advance.

What [the Chart Method] does purport to achieve is to show us explicitly in a single compass how we do reason and believe for those individual facts and from them to the final fact. To achieve this much would be a substantial gain, in the direction of correctness of belief. Each separate proffered fact is tested in our consciousness, and the result is recorded. Perhaps we cannot explain why we reach that result, but we know at least that we do reach it . . . Hence, though we may not be able to demonstrate that we ought to reach that belief or disbelief, we have at least the satisfaction of having taken every precaution to reach it rationally. Our moral duty was to approximate, so far as capable, our belief to the fact. We have performed that duty, to the limits of our present rational capacity. $(\$ 28$, p. 51$)$

Although its primary use may be for deciders, to represent the actual/ideal process of reasoning, the Chart has a use also for advocates. The judicial proof modeled by the Chart is not just a mental process, it is a "process of contentious persuasion,-mind to mind, counsel to Judge or juror, each partisan seeking to move the mind of the tribunal" $(\$ 1$, p. 3 , see also $\$ 2$, p. 6$)$. A Chart of the decider's mental process can serve as a tool for the advocate because of an additional optimistic working assumption that Wigmore makes. According to Wigmore, the advocate's discourse has the primary function of showing the decider what mental process to engage. As he says:

When the evidence is all in, the counsel sets himself to his ultimate and crucial task, i.e. that of persuading the jury that they should or should not believe the fact alleged in the issue. To do this, he must reason naturally, as all men reason and as juries can be shown how to reason. $(\S 1$, p. 5 ; see also $\S 13$, p. $27 ; \$ 4$, p. 10$)$

Courtroom persuasion, in Wigmore's view, is not a matter of tricks or deception, but of laying out a manifest inferential path for the jury to follow. Wigmore is therefore able to treat as isomorphic the several mental processes represented by the Chart and the "points of view" or argumentative moves being made by the parties at the trial (see $\$ 11$, p. 23 et seq.).

Again, however realistic a notion this may be of persuasion in general, there is some reason to credit Wigmore's optimistic assumption in the trial setting. Wigmore could (though he does not) argue that the trial indeed constrains the advocate to using only rational means of persuasion: in part by rules, but even more by the presence of an opposing advocate who will point out any lapses. The advocate thus has a practical necessity, if not a "moral duty," to keep her persuasive talk. close to proof.

One might say, in summary, that the conditions which would make Wigmore's two optimistic assumptions plausible are institutionalized in the trial. As long as Wigmore adopts a strategy of "localism," aiming to capture only what happens at trial, his Charts may indeed represent equally well the structure of the proof, of the 
decider's thinking, and of the advocate's arguing. In contrast to the desire of informal logicians to deal with "all arguments" (thus Freeman, 1991, p. 34), such a strategy of "localism" has always been characteristic of the classical rhetorical tradition. Going back to Aristotle (Rhetoric. 1.3), rhetorical theorists do not study argumentation in general or globally; they study different "species" or "forms" or "genres" of practice roughly (very roughly) as institutionalized in the world. Wigmore in fact seems to be limiting himself to what Aristotle termed "forensic rhetoric": the arguing that arises after an accusation, addressed to those who will decide what happened ("past fact") in order to achieve a just outcome. This limitation of interest means of course a limitation in results, but it also gives some hold on problems that, unlimited, may prove more difficult.

\section{Where to start?}

Consider, for another example, the contemporary debate over whether in assessing the soundness of an argument we need to confirm that its premises are true or only acceptable to the audience addressed-what Ralph Johnson has called the "Integration Problem" (Johnson, 2000). By his strategy of "localism," focusing exclusively on judicial proof, Wigmore is able not only to finesse this difficulty but even to avoid addressing the question of premise quality at all. In the specific context of a trial, Wigmore can justifiably take the ultimate starting points of reasoning to be derived from things immediately present to the decider-from the evidence, that is, the things made evident at trial. The testimony of witnesses makes up the bulk of this class; also included are other objects made present by what Wigmore barbarously calls "autoptic proference," or "offering before the very eyes" of the decider $(\S 5$, p. 11). Statements about the perceptible qualities of these evident things are likely to be both true in a straightforward empirical way and accepted by those to whom they were evident. For example, assume that the victim in open court testifies that the accused was his assailant. It is then true that the victim so said. It is also very likely that the jurors will accept the proposition that the victim so said. Of course, what if any conclusion to draw from the evidentiary fact may be highly contestable; the identification may turn out to be a misidentification. My point is only that everyone present at trial is licensed to take everything made evident there for granted. Thus it becomes unnecessary in these circumstances to develop any method for assessing the quality of ultimate premises, whether by acceptability, truth or any other criterion.

Part of the Chart Method's usefulness is that it allows its user to check that all her lines of argument rest on such granted ultimate starting points. She need only inspect the Chart's arrangement of shapes. "Are all the bottommost shapes squares (or marked with a " " or "I")?" the Charter must ask; and if they are, the argument passes this test. 


\section{Why Chart?}

Current proponents of tree diagramming are often committed to diagramming the structure of arguments made. The diagram in this view is a tool for analyzing and assessing already existing arguments. This means that the diagrammer will very often face significant problems of interpreting the argument, since argumentative discourse in practice must commonly be significantly "transformed," "standardized" or "reconstructed" to reveal anything like a tree structure. In particular, the diagrammer must decide how much "charity" to exercise, say by inserting additional premises, when the structure of the argument as made appears otherwise unsound (e.g., Govier, 1987, Ch. 5).

Overall, Wigmore's Chart Method shifts the center of gravity of the diagramming scheme from interpreting arguments already made to designing, constructing, creating or (in classical terms) inventing arguments/reasons to be made. As discussed above, the Charter is supposed to be trying to decide a case or to discover how it could be decided; she prepares the Chart in order to help herself assess and improve her argument as she develops it. And this again reflects the orientation commonly adopted by rhetorical theorists. The study of rhetoric began (so the myth runs) when someone discovered how much money he could make helping his fellow citizens improve their arguments at trials. Even today, the typical argumentation textbook in the American debate tradition aims to prepare the student to present her views to others; the skills of argument interpretation and reconstruction are not stressed, if they are present at all.

The rhetorical approach is of course not without its own problems. Where argument reconstruction raises the problem of charity, argument (or reasoning) invention raises the problem of "how low do you go"--how detailed or ramified does the Charter allow her Chart to become. As already noted, Wigmore is determined to have his Charts "include all the evidential data presentable in a given case" $(\$ 27, \mathrm{p} .48)$. One of the main purposes of the Chart is indeed to allow the Charter visually to inspect many more relations among propositions than she could otherwise hold in mind; to reach, "by conscious juxtaposition" or "coördination," the "simultaneous possession of a multitude of facts" ( $\$ 26$, p. 47). As a result, a Wigmorean Chart can be quite large, very much in contrast with what Johnson has pointedly termed the "snippets" that tend to be the object of attention among informal logicians (1996, p. 67). One instructor, for example, reports his student's effort stretched for 37 feet (Twining, 1994, p. 18), and I have received a Chart with 613 numbered propositions. But greatness has its burdens. Wigmore's Chart Method encourages the construction of a diagram much more complex than is likely to be necessary, in any of several senses: far more than is needed to persuade, to judge the case soundly within a fair time for the parties and so on. ${ }^{3}$ So in place of principles of charitable reconstruction of arguments, the Wigmorean arguer/decider needs principles of selection. 
Alas, Wigmore himself offers none. But it is interesting to note that something like such principles are currently receiving attention from argumentation theorists. A recent exchange between Ralph Johnson (2000), Trudy Govier (1999, chap. 12, 13) and Fred Kauffeld (1998; forthcoming) has begun exploring the basis and extent of an arguer's "dialectical obligations"--or in the vocabulary of the rhetorical tradition, her burdens of proof. How far need an arguer develop her argument in detail? What doubts and objections against it need she meet? Although some of the discussion has been oriented towards assessing whether an existing argument fulfills the obligations, the principles emerging would seem to be as much or more at home as part of a theory oriented towards argument invention. For while charity is an obligation imposed on or undertaken by one interpreting another's argument, dialectical obligations are imposed on or undertaken by the producer of argument.

In sum, while the strategy of "localism" characteristic of the rhetorical tradition allows Wigmore to ignore distinctions made within informal logic, the orientation towards production, also typically rhetorical, causes a new problem to become visible, though one we are beginning to assail.

\section{The Chart and assessing the quality of argument}

One of the main uses of any representational scheme is to force into salience such features of an argument as are important to assess, and from the point of view of invention, improve it. Speaking very broadly, there seem at present to be two approaches to assessment. The first assesses the quality of an argument by the quality of its components: the argument's internal soundness. The quality of an argument displayed in a tree diagram, for example, is a function of the quality of its circles and arrows. The second approach, by contrast, assesses the quality of an argument by testing the extent to which it can resist refutation (Perelman, 1969, p. 461): the argument's external strength. The more and better the doubts and objections an argument can meet, the better it is. (This is, after all, the way we measure strength in other contexts: we don't dissect a person's arm, we see how much she can lift.) Wigmore, as the next section will argue, is a decided proponent of the external strength method for assessing arguments. But this creates a problem for his diagramming scheme. How can a Chart represent in perspicuous order not only all the reasons for a conclusion, but also all reasons against them, and all the reasons against them, and so on? ? $^{4}$ In the final section, I explore Wigmore's proposed solution to this problem.

\section{Wigmore on the expression of inference warrants}

We have already seen that Wigmore does not, in the context of judicial proof, need a method for assessing the quality of the ultimate premises of an argument. But he still might develop a method for assessing internal soundness by assessing the quality of the reasoning from these premises to the ultimate conclusion. Many contemporary diagramming schemes take this route, encouraging the diagrammer 
to make explicit the reason why the premise supports, warrants or is relevant to the conclusion as a step in the assessment of the argument's soundness. Thus the Toulmin diagram (1958) requires the diagrammer to express an inference warrant. And while James Freeman opposes this as a requirement, he goes on to argue that the diagram ought at least to permit the representation of relevancy claims through the use of multiple premises represented in linked, as opposed to merely convergent, argument structures (1991, §4.4).

Wigmore, in contrast, is adamant that such inference warrants should never (or very seldom) be expressed when building a Chart. According to Wigmore, there are two general "forms of Argument": the "Deductive," which includes a generalization of some sort, and the "Inductive," which moves "immediately" from "a single or isolated fact" to a conclusion $(\$ 9$, p. 20$)$. For example:

["Deductive"] "Persons related by blood to a party are biassed in their testimony" (major premise); "This witness is related by blood to a party" (minor premise); "Therefore, this witness is biassed in his testimony" (conclusion).

["Inductive"] "This witness is related by blood to a party" (thesis); Therefore, he is biassed in his testimony" (conclusion). ( $\$ 9$, p. 17-8) Now, "a brief examination will show that in the offering of evidence in court the form of inference is always inductive" $(\S 9$, p. 19). Wigmore gives two reasons for this claim. First, although "every inductive inference is at least capable of being transmuted into and stated in the deductive form, by forcing into prominence the implied law or generalization on which it rests more or less obscurely," still, doing that would distort the argument being Charted. "It is not a question of what the form might be," Wigmore continues, "but of what it is, as actually employed; and it is actually put forward in inductive form" ( $\$ 9$, p. 20$)$. Second, even if the inference warrant could be expressed, expressing it "would be useless. We should ultimately come to the same situation as before," Wigmore argues. For it would remain "for the Court to declare whether it accepts the major premise," and that would require again, "after all," another "inductive" inference.

So with all other evidence when resolved into the deductive form; the transmutation is useless, because the Court's attention is merely transferred from the syllogism as a whole to the validity of the inference contained in the major premise; which presents itself again in inductive form. ( $\$ 9$, pp. 20-1)

"For practical purposes," Wigmore concludes, "it is sufficient to treat the use of litigious evidentiary facts as generally inductive"- that is, non-inference-warrantexpressing - "in form" $(\$ 9$, p. 21$){ }^{6}$

The one exception to the exclusion of inference warrants Wigmore seems to allow is when the generalization can itself be supported by something more than references to ordinary experience or common sense. When, for example, an expert (in "testimonial psychology," $\$ 10$, p. 21 ) can testify that another witness could not have seen what he said he saw, then the generalization-something like 
"correct vision from such a location is impossible"-supported by the expert's testimony should be included in the Chart $(\$ 10 ; \S 35$, p. 60). Indeed, Wigmore even sneaks in an additional symbol to cover such situations: generalizations are indicated by a shape in the form of a capital "D" (e.g. $\$ 49$, p. 89 ) or alternately by a circle marked with a small "d" $(\$ 35$, p. 60$)$.

Wigmore certainly overstates his case here; arguers in courtroom settings do assert and defend common sense inference warrants, and any diagramming scheme is going to have to confront that fact, "for practical purposes." I am looking here, however, not for Wigmore's problems, but for his solutions. Given that he rejects the explicitization of inference warrants as an aid to the assessment of an argument's internal soundness, how is the Chart supposed to help the Charter assess the external strength of her reasoning?

\section{Charts and the resolution of doubts}

In Wigmore's view, what must be forced into expression through Charting are not the reasons for belief but for disbelief. Echoing Sidgwick, he pronounces:

The process most needed for correct thinking on pieces of evidence is the analysis of inferences. When we have dissected and laid out explicitly the several steps of sub-conscious reasoning, then and then only can we discern the possibilities of fallacious inference. . . . It is thus only by careful dissection of the implicit steps of inference that we can lay bare and locate the possibilities of doubt. ( $\$ 7, \mathrm{pp} .13-4)$

And Wigmore asks:

What are the peculiar dangers of the inference, the loopholes for error, the opportunities for false inference? By ascertaining these, we shall learn what safeguards or tests ought to be applied by the jurors in weighing the evidence, and what opportunities of counter-inference are offered to the opponent. $(\$ 11, \mathrm{p} .22)$

"The peculiar danger . . . of Inductive Inference," Wigmore concludes "is that there may be other explanations, than the alleged . . . one, for the fact taken as the basis of proof" ( $\$ 11$, p. 23$)$.

Wigmore thus takes coming to belief to be a systematic process through which alternative inferences are considered and rejected ( $\$ 23, \mathrm{pp} .43-4)$. So instead of requiring express inference warrants, the Chart Method allows the strength of an inferential step to be checked by making express the considerations that might weaken the inferential step and showing whether they can be refuted. In addition to the main, vertical, thrust of the Chart, Wigmore adds a horizontal dimension testing whether the evidence can be explained away. Possible hypotheses explaining away some evidence ("Explanations"), and their support, are Charted to the left of an inference; reasons ruling out these Explanations, and their support, are Charted to the right. The strength of the vertical step is made evident negatively, by contrast with these horizontal ramifications. Thus the Charter can begin to 
assess her inferences by making simple visual checks, such as: "Is there a triangle off to the left of this circle (i.e., is there a possible Explanation explaining away the evidence)?" and "Is there a triangle off to the right balancing that one off to the left (i.e., can the Explanation be ruled out)?"

Allow me to add a bit of experiential evidence. From using Wigmorean Charts, and helping students use them, it does seem that this aspect of Wigmore's Method works, at least for what he's calling judicial proof. Each inferential step is defined as the overcoming of a determinate doubt or doubts; no doubt, no need to represent a step. Where the Charter wants to represent a step, in turn, it is highly likely that there is some as-yet unexpressed doubt being overcome, and the Chart encourages it to be made evident and inspected.

Consider the following example, adapted from the imperial Roman schoolmaster, Quintilian (Inst. 5.9.9):

[1] There is blood on this man's cloak.

[2] Therefore, he was involved when the victim was stabbed to death. There does seem to be something to this argument: we've caught the man if not red-handed at least red-coated. How can we test the argument's strength? By forcing to notice an inference license?-something like:

[3'] People with bloody cloaks likely have been involved when victims are stabbed to death.

This, however, seems to confuse the argument. First, I can't claim much experience with bloody clothes or murders; and second, based on what experience I have, I would say this generalization is false. What Wigmore is proposing is a process for testing the argument that requires making express things like this:

[3] Objection: His cloak was stained when he sacrificed a chicken.

[4] Reply: He didn't sacrifice a chicken.

[5] Evidence: His neighbor testifies that he's an atheist and never sacrifices.

[6] Objection: It was stained from a nosebleed.

[7] Reply: He didn't have a nosebleed.

[8] Evidence: A doctor testifies that he examined the nose and found it sound.

-and so on; as Charted in Figure 2. The initial argument may or may not survive this destructive testing, but at least it's not being misrepresented.

Wigmore's Chart Method of diagramming and assessment bears a family resemblance to Popperian "elimination logic" and the nonmathematical account of probability judgments offered by Jonathan Cohen (1977). All trace some ancestry to pragmatism and its emphasis on reasoning as the resolution of doubts, an ancestry in Wigmore's case mediated by Sidgwick. 
Figure 2. A Wigmorean Chart of the "bloody cloak" argument.

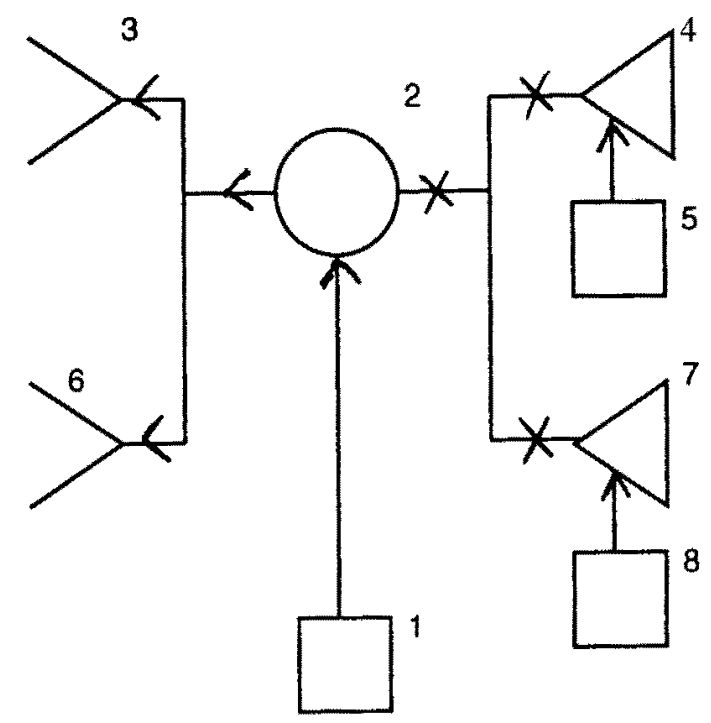

Wigmore's Method also bears a family resemblance to the contemporary attempts to capture objections and responses to objections within the confines of a tree diagram. But where several of the current proposals represent only the objections (Govier, 1997; Toulmin, 1958) or only the responses (Snoeck Henkemans, 1992), the Wigmorean Chart succeeds in representing both. It does so, furthermore, without visually collapsing the objections and responses into the primary argument for the conclusion, as do some contemporary schemes (Govier, 1997; Johnson \& Blair, 1994; Snoeck Henkemans, 1992). Wigmore's Method seems to be closest to that of James Freeman (1991), who has also devised a method for representing objections orthogonal to the main line of the argument.

The Chart Method is not without its weaknesses, however. To cite again my personal experience, Charting seems to work well when the ultimate conclusion is competing with the "null hypothesis": say, when the ultimate conclusion "X did it!" is being compared with " $\mathrm{X}$ did not do it!" The Chart does not work as well when the competing conclusion is an alternative theory explaining the same facts, as for example the conclusion that "Y did it, and framed X!" Then, instead (for example) of each testimonial fact being explained away for a different reason, it is explained away as suborned as part of Y's nefarious plan. But Charting this is cumbersome. The Charter either has to incorporate the entire sub-diagram supporting the nefarious plan horizontally to the left of each item of testimony, or has to oversimplify, say by repeatedly re-using the proposition (diagrammed somewhere else) that $Y$ framed $X$, without further elaboration. Either way, the strength 
of the (vertical) inference can no longer be inspected visually by examining the (horizontal) elimination of doubts, and the Chart begins to lose its heuristic value.

Perhaps an even more "connectionist" or "holistic" model is required to represent the argument in such cases. Conventional argument tree diagrams are one dimensional, allowing the move from premise to conclusion; Wigmorean Charts are two dimensional, allowing in addition the move between conclusion, Explanation and ruling-out; something like Thagard's ECHO system for modelling explanation-seeking is n-dimensional, allowing each proposition to connect or move with all the others (Thagard, 1995). If our assessment of the strength of the argument from one piece of evidence often depends in part on our assessment of the strength of the rest of the case (as Quintilian thought, Inst. 5.9.10), then something like this last approach will be necessary to accurately represent judicial proof. The technology such a system requires, however, is far more than pencil and paper, so it may be a while before that complex a representational scheme will become performable by ordinary arguers/deciders. Meanwhile, Wigmore's Chart Method seems an advance.

\section{Conclusion}

Whither did Wigmore's Chart Method go?The answer seems to be: "nowhere." Aside from an oral tradition said to be passed down within the American intelligence community (Tillers \& Schum, 1988, p. 914 n. 14), Wigmore's Principles fell like a "lead balloon," with "almost no visible impact on American legal thought, on legal education or on evidence scholarship" (Twining, 1985, p. 164). Its effect on students of rhetoric was similarly nil. Among philosophers, Rescher cited the book once as "that classic work on legal reasoning" (1977, p. 26, n. 2), but appears not to have used it extensively. In particular, it seems clear that Beardsley himself did not draw from Wigmore or from anyone who did; his invention of tree diagramming was entirely independent.

More recently, Wigmore's work has been dug up by David Schum, who in the late 1960's discovered the Principles in the library basement and has since been touting it among decision theorists and the artificial intelligence community (1990). Within legal scholarship, Wigmore has also been revived by William Twining and Terry Anderson, authors of a new textbook based on the Chart Method (1991, 1998), and by Peter Tillers, the editor of the latest edition of Wigmore's Treatise.

But what influence should Wigmore have? Twining (1994, chap. 2) has argued strongly that jurisprudence owes more attention to the Principles of Judicial Proof than it has hitherto paid. The burgeoning study of legal argumentation, especially in Europe (see Feteris, 1999), has been concerned primarily with reasoning about legal norms. This is probably in part because in civil law systems, fact-finding proceeds less by argument than by inquiry; further, the question of how an interpretation of a norm can be justified bears closely on the question of how a norm 
can be considered legitimate at all-a line of inquiry flourishing since Habermas. The very complexity of Wigmore's Chart Method, however, suggests that students of legal argumentation will need to pay closer and more nuanced attention to the way factual conclusions can be justified; there are ways of argument here that ought to be accounted for within any theory that claims generality.

Within the informal logic community, Wigmore's rhetorical approach to the problems of argument diagramming and assessment should at least be worth a second look. His strategy of "localism" appears especially promising. By focusing only on argumentation within one practically defined context - the trial-Wigmore eliminates a pair of challenges to contemporary theory. At trial, argument, inference and proof can be treated as identical because participants are obligated to make their arguments parallel their inferences and their inferences, their proof. Again, at trial events are so arranged that a wealth of premises both true and acceptable are available to all. In both instances, problems which have been considered problems for argumentation theory in Wigmore's rhetorical perspective prove to be problems solved by a specific argumentative practice. It would be interesting to discover whether different solutions to these two problems have been developed in other argumentative "locales," and further, whether other problems troubling contemporary argumentation theory might be resolved by a similarly rhetorical approach. In particular, we have seen Wigmore sketching the beginnings of an account of the obligations participants undertake or have imposed upon them in the trial setting. This account, if more fully worked out, might specify the "local" nature and limits of those other troubling burdens on arguers: the obligation to interpret with charity and the obligation to respond to doubts and objections.

The Chart Method itself also deserves further consideration. It is now commonly asserted that arguments are in some deep way built by responding to doubts and objections-or, as it's often put, that argument structure is essentially dialectical (e.g., Freeman, 1991; Johnson, 2000; Snoeck Henkemans, 1992). This approach obviously opens the question of how the tree diagram can be modified to incorporate material beyond the "illative core" (Johnson, 2000) of premises and conclusions; a question that will become still more difficult to answer as closer attention is given to the many different sorts of doubts and objections that arguers in fact raise (as in Govier, 1999, Chap. 13). Several proposals for diagramming the dialectical aspects of argument have currently entered the lists; a full contest of their relative merits is beyond the scope of this paper, although I hope it's clear that when such a trial is made, Wigmore's Chart Method will be counted a contenderperhaps after some revisions.

For it's easy enough to suggest improvements-simplifications mostly--to Wigmore's overloaded diagramming scheme. All the belief markers should be dropped, along with all indications of who presented the evidence or which side it supports; arrows should be used to represent all relations (for similar suggestions, 
see Anderson \& Twining, 1998, p. 144-146). Some of the Wigmorean surplusage, however, is actually useful. The Beardslian tree diagram may be too austere to represent the complexities of argument, especially on the scale that the Chart Method intends. At least within the limited context of judicial proof, it seems worthwhile to retain the squares to represent evidence and the horizontal system of triangles to represent objections to the inferential step and refutations of these objections.

But perhaps the primary conclusion to be drawn from Wigmore's Chart Method is that argument diagramming is a robust response to some of the problems of argument analysis and production. The tree diagram must capture such features of arguing as twentieth century folk found salient; at least that is what its independent invention by two very differently trained minds suggests.

\section{References}

Anderson, T. and W. Twining. (1991), Analysis of Evidence: How to Do Things with Facts, Based on Wigmore's Science of Judicial Proof. Boston, MA: Little, Brown \& Co.

Anderson, T. and W. Twining. (1998). Analysis of Evidence: How to Do Things with Facts, Based on Wigmore's Science of Judicial Proof. Evanston, IL: Northwestern University Press.

Beardsley, M. (1950), Practical Logic. New York, NY: Prentice-Hall.

Cohen, L.J. (1977). The Probable and the Provable. Oxford: Oxford University Press.

Copi, I.M. (1995). Reconciliation of formal and informal logic. In F.H. van Eemeren, R. Grootendorst, J.A. Blair and C.A. Willard (Eds.), Perspectives and Approaches: Proceedings of the Third ISSA Conference on Argumentation (pp. 84-94.). Amsterdam: Sic Sat.

Eemeren, F.H. van and R. Grootendorst. (1992). Argumentation, Communication and Fallacies: A Pragma-dialectical Perspective. Hillsdale, NJ: Lawrence Erlbaum.

Feteris, E. (1999). Fundamentals of Legal Argumentation: A Survey of Theories on the Justification of Judicial Decisions. Dordrecht: Kluwer.

Freeman, J.B. (1991). Dialectics and the Macrostructure of Arguments: A Theory of Argument Structure. Berlin: Foris Publications.

Govier, T. (1987). Problems in Argument Analysis and Evaluation. Dordrecht: Foris Publications.

Govier, T. (1997). A Practical Study of Argument (4th ed.). Belmont, CA: Wadsworth Publishing.

Govier, T. (1999). The Philosophy of Argument. Newport News, VA: Vale Press. Johnson, R.H. (1996). The Rise of Informal Logic. Newport News, VA: Vale Press.

Johnson, R.H. (2000) Manifest Rationality: A Pragmatic Theory of Argument. Mahwah, NJ: Lawrence Erlbaum. 
Johnson, R.H. (in press). More on Arguers and their Dialectical Obligations. In Proceedings of the Third OSSA Conference [CD-ROM].

Johnson, R.H. and J.A. Blair. (1994). Logical Self-Defense (US Edition). New York, NY: McGraw-Hill.

Kauffeld, F. J. (1998). Rhetorical Invention and the Speaker's Selection of Arguments. In J.F. Klumpp (Ed.), Argument in a Time of Change: Definitions, Frameworks, and Critiques (pp. 35-9). Annandale, VA: National Communication Association.

Kauffeld, F.J. (in press). Dialectical Tier Argumentation as Structured by Proposing and Advising. In Proceedings of the Third OSSA Conference [CD-ROM].

Nielsen, F.S. (1997). "Summary" [English] (pp. 399-407). In Alfred Sidgwicks Argumentationsteori. Copenhagen: Museum Tusculanums Forlag.

Perelman, Ch. and L. Olbrechts-Tyteca. (1969). The New Rhetoric: A Treatise on Argumentation. Notre Dame, IN: University of Notre Dame Press.

Pinto, R.C. (1995). The Relation of Argument to Inference. In F.H. Van Eemeren, R. Grootendorst, J.A. Blair, C. Willard (Eds.), Perspectives and Approaches: Proceedings of the Third ISSA Conference on Argumentation (pp. 271-85). Amsterdam: Sic Sat.

Rescher, N. (1977). Dialectics: A Controversy-Oriented Approach to the Theory of Knowledge. Albany, NY: SUNY Press.

Schum, D. (1990). Inference Networks and their Many Subtle Properties. Information and Decision Technologies, 16, 69-98.

Sidgwick, A. (1884). Fallacies: A View of Logic from the Practical Side. New York, NY: D. Appleton \& Co.

Snoeck Henkemans, A.F. (1992). Analysing Complex Argumentation: The Reconstruction of Multiple and Coordinatively Compound Argumentation in a Critical Discussion. Amsterdam, Sic Sat.

Thagard, P.R. (1995). Explanatory Coherence. In A.I. Goldman (Ed.), Readings in Philosophy and Cognitive Science (pp. 153-83). Cambridge, MA: MIT Press.

Thomas, S. (1977). Practical Reasoning in Natural Language. Englewood Cliffs, NJ: Prentice-Hall.

Tillers, P. and D. Schum. (1988). Charting New Territory in Judicial Proof: Beyond

Wigmore. Cardozo Law Review, 9, 907-66.

Toulmin, S. (1958). The Uses of Argument. Cambridge: Cambridge University Press.

Twining, W. (1985). Theories of Evidence: Bentham and Wigmore. Stanford, CA: Stanford University Press.

Twining, W. (1994). Rethinking Evidence: Exploratory Essays. Evanston, IL: Northwestern University Press.

Venn, J. (1894). Symbolic Logic. London: MacMillan and Co.

Walton, D. (1996). Argumentation Schemes for Presumptive Reasoning. Mahwah, NJ: Lawrence Erlbaum.

Wigmore, J.H. (1913). The Principles of Judicial Proof, As Given by Logic, Psychology, and General Experience and Illustrated in Judicial Trials (1 ${ }^{\text {st }}$ ed.). Boston, MA: Little, Brown \& Co. 
Wigmore, J.H. (1931). The Principles of Judicial Proof, or The Process of Proof, as given by Logic, Psychology and General Experience and Illustrated in Judicial Trials ( ${ }^{\text {nd }}$ ed.). Boston, MA: Little, Brown \& Co.

Wigmore, J.H. (1937). The Science of Judicial Proof, As Given by Logic, Psychology, and General Experience and Illusirated in Judicial Trials ( $3^{\text {td }}$ ed.). Boston, MA: Little Brown \& Co.

Wigmore, J.H.(1983). Evidence in Trials at Common Law (P. Tillers, Ed.). Boston, MA: Little, Brown \& Co.

\section{Author's Note}

I thank the 1998 Seminar in Legal Argumentation at Northwestern University for inciting several points canvassed in this paper, and Prof. F.S. Nielsen for generously sharing his knowledge of Alfred Sidgwick.

\section{Notes}

Wigmore's work went through two editions as The Principles of Judicial Proof, being renamed The Science of Judicial Proof in the third (1937) and final edition. In-text citations refer to pages and section numbers in the second (1931) edition, which has the most thorough and organized discussion of the Chart Method. The interested reader can locate parallel material in the Introduction and Part III of the first (1913) edition, and in Parts I and Chapter XXXI of the third edition. In addition, the more readily available Part I, Chapter 3 of Wigmore's Treatise includes some of the same discussion of principles, minus the Chart Method, and large parts of the relevant material have been reprinted in Anderson \& Twining (1991, 1998).

"Of course, anyone can use the word "rhetoric," and nowadays, anyone does. In this paper, I take as "rhetorical" any aspect of the tradition of sustained reflective thought on the human capacity to persuade in civic settings. I take as paradigmatic moments in this tradition the rhetorical manuals of classical antiquity and the contemporary American debate textbooks.

${ }^{3}$ The cause of the Chart's unruly growth can in fact be stated more explicitly. As argued later in this paper, the Wigmorean Chart is constructed through raising and meeting doubts, and there are always more doubts. For example, the Charter might consider at every step the " $\mathrm{X}$ Files Doubt": that any given occurrence is really accounted for by a vast and hidden conspiracy, or by Martians, or by both-an updated version of the "absurd" doubts Wigmore suggests at $\$ 17, \mathrm{p}$. 36.

${ }^{4}$ It should be noted that the other major method for representing argument structure-argument schemes (c.g., van Eemeren et al., 1992; Walton, 1996-may be able to handle the problem of representing objections and responses with more ease via lists of standard "critical questions."

"According to Peter Tillers, Wigmore got this conception of "induction" and "deduction" from J.S. Mill; "silly talk," as Tillers says, which tends to mask for contemporary readers an important question about the need to express inference warrants. See Wigmore, 1983, vol. $1 \mathrm{~A}, \$ 37.4$, p. 1038 , n. 16.

'It is surprising to find David Schum, one of Wigmore's few contemporary readers, attributing to him the "necessity for asserting generalizations that, in effect, supply the 'glue' that holds our arguments together" ( 1990, p. 96; see also p. 72). Within the legal academy, on the other hand, Wigmore's actual view has been recognized and criticized. Wigmore's opponents there have argued that it is useful to force the argument into "deductive" form in order to draw attention to 
and test the implicit generalization (see the summary of the debate in Tillers, 1983 at $\$ 30, \mathrm{n} .1$, 5 and pp. 96-8; \$37). These critics, however, have apparently overlooked the fact that Wigmore's Chart Method does provide a way for testing inferential steps; for which, see the next section of this paper.

'On Sidgwick's ties to early British pragmatism, see Nielsen, 1997.

\author{
Jean Goodwin \\ Department of Communication Studies \\ Northwestern University \\ 1815 Chicago Avenue \\ Evanston, IL 60208 U.S.A. \\ jeangoodwin@nwuedu
}

